Pacific Journal of Mathematics

INTEGRAL INEQUALITIES FOR FUNCTIONS WITH 


\title{
INTEGRAL INEQUALITIES FOR FUNCTIONS WITH NONDECREASING INCREMENTS
}

\author{
H. D. BRunK
}

1. Introduction. One of the fundamental inequalities of analysis is Jensen's inequality,

$$
\int f(x) d G(x) \geqq f\left(\int x d G(x)\right),
$$

for convex $f$, with $G$ a probability distribution function. However, $G$ need not be a probability distribution function in order that (1.1) hold for all convex $f$. Let $X(t)$ be nondecreasing for $\alpha \leqq t \leqq \beta$. It was shown in [1] that under mild regularity conditions on $G$, if $G(\alpha)=0$, necessary and sufficient conditions for

$$
\int_{\alpha}^{\beta} f[X(t)] d G(t) \geqq f\left(\int_{\alpha}^{\beta} X(t) d G(t)\right)
$$

for all convex $f$ are

$$
G(\beta)=1,
$$

and

$$
\int_{\alpha}^{t} G(u) d X(u) \geqq 0, \quad \int_{t}^{\beta}[1-G(u)] d X(u) \geqq 0 \quad \text { for } \alpha \leqq t \leqq \beta .
$$

This result was applied to show that:

(i) sufficient conditions in order that (1.2) hold for convex $f$ are $X(\alpha)=0, f(0) \leqq 0$, and $0 \leqq G(t) \leqq 1$ for $\alpha \leqq t \leqq \beta$; and

(ii) if $f$ is convex on $[0, b]$ with $f(0) \leqq 0$, if $0 \leqq a_{1} \leqq \cdots \leqq a_{m} \leqq$ $b$, if $0 \leqq h_{1} \leqq \cdots \leqq h_{m} \leqq 1$, then

$$
\sum_{j=1}^{m}(-1)^{j-1} h_{j} f\left(a_{j}\right) \geqq f\left[\sum_{j=1}^{m}(-1)^{j-1} h_{j} a_{j}\right] \text {. }
$$

The latter, (ii), was proved independently by Olkin [5]. Ciesielski [2] obtained results (under unnecessarily stringent hypotheses) related to (i) through change of variable, and obtained also analogous two-dimensional results. These provided part of the motivation for the present study of $k$-dimensional analogues of (1.2).

In the present paper, $X(\cdot)$ denotes a map from the real interval $[\alpha, \beta)$ into an interval $I$ in $k$-dimensional Euclidean space $R^{k}$ such that each component of $X$ is nondecreasing. The function $f$ is a map from

Received November 29, 1963. This research was supported by the United States Air Force Office of Scientific Research. 
$R^{k}$ into the reals. The property of $f$ critical for inequality (1.2) in this context is that of having nondecreasing increments, rather than convexity; for $k=1$ it coincides with convexity. Functions with nondecreasing increments are discussed briefly in $\S 2$. In $\S 3$, conditions (1.3) and (1.4) are shown to be necessary and sufficient for (1.2) $(k \geqq 1)$, and $k$-dimensional analogues are given of (i) and (ii), above. Section 4 is devoted to the $k$-dimensional analogue of a related theorem of Levin and Stečkin [4], giving conditions on $H$ necessary and sufficient in order that $\int_{\alpha}^{\beta} f[X(t)] d H(t) \geqq 0$ for all $f$ with nondecreasing increments.

2. Functions with nondecreasing increments. Let $R^{k}$ denote the $k$-dimensional vector lattice of points $x=\left(x_{1}, \cdots, x_{k}\right), x_{i}$ real for $i=$ $1,2, \cdots, k$, with the partial ordering $x=\left(x_{1}, \cdots, x_{k}\right) \leqq y=\left(y_{1}, \cdots, y_{k}\right)$ if and only if $x_{i} \leqq y_{i}$ for $i=1,2, \cdots, k$.

DEFINITION 2.1. A real-valued function $f$ on an interval $I \subset R^{k}$ will be said to have nondecreasing increments if

$$
f(a+h)-f(\alpha) \leqq f(b+h)-f(b)
$$

whenever $a \in I, b+h \in I, 0 \leqq h \in R^{k}, a \leqq b$. Even in the one-dimensional case, $k=1$, this does not imply continuity. Indeed, every solution of Cauchy's equation, $f(x+y)=f(x)+f(y)$, has equal increments. (Note that if $f_{1}, f_{2}, \cdots, f_{k}$ are functions of a single real variable satisfying Cauchy's equation, then $f(x) \equiv \sum_{i=1}^{k} f_{i}\left(x_{i}\right)$ is a function on $R^{k}$ satisfying Cauchy's equation.) However, our interest in this paper is solely in continuous functions with nondecreasing increments.

It is of interest to note that such a function is convex along positively oriented lines, i.e., lines whose direction cosines are nonnegative, with equations of the form $x=a t+b$ where $(0, \cdots, 0) \leqq a \in R^{k}, b \in R^{k}$. If $f(x)$ is continuous with nondecreasing increments for $b \leqq x \leqq a+b$, set $\varphi(t)=f(a t+b), 0 \leqq t \leqq 1$. In order to prove $\varphi$ convex, it suffices [3, Theorem 86, page 72] to show that $[\varphi(r)+\varphi(s)] / 2 \geqq \varphi[(r+s) / 2]$ for $0 \leqq r \leqq s \leqq 1$. Set $c=(s-r) / 2$. Then $\varphi(s)-\varphi[(r+s) / 2]=$ $\varphi(r+2 c)-\varphi(r+c)=f(a r+b+2 c a)-f(a r+b+c a) \geqq f(a r+b+c a)-$ $f(a r+b)=\varphi(r+c)-\varphi(r)=\varphi[(r+s) / 2]-\varphi(r)$. Thus $\varphi$ is convex.

It is immediate from the definition that if the partial derivatives $f_{i}(x) \equiv \partial f / \partial x_{i}\left(x_{1}, \cdots, x_{k}\right)$ exist for $x \in I$, then $f$ has nondecreasing increments if and only if each of these partial derivatives is nondecreasing in each argument; in other words, if and only if the gradient, $\nabla f \equiv$ $\left(f_{1}(x), \cdots, f_{k}(x)\right)$ is nondecreasing on $I$. The second partials, if they exist, are then nonnegative. If $f$ is continuous and has nondecreasing increments on $I$, it may be approximated uniformly on $I$ by polynomials having nondecreasing increments and therefore nonnegative second 
partial derivatives. To see this, let us set, for convenience, $I=$ $\left\{x: x \in R^{k},(0, \cdots, 0) \leqq x \leqq(1, \cdots, 1)\right\}$. It is known that the Bernstein polynomials

$$
\sum_{i_{1}=0}^{n_{1}} \sum_{i_{2}=0}^{n_{2}} \cdots \sum_{i_{k}=0}^{n_{k}} f\left(i_{1} / n_{1}, i_{2} / n_{2}, \cdots, i_{k} / n_{k}\right) \prod_{j=1}^{k}\left(\begin{array}{c}
n_{j} \\
i_{j}
\end{array}\right) x_{j}^{i} j\left(1-x_{j}\right)^{n_{j}-i_{j}}
$$

converge uniformly to $f$ on $I$ as $n_{1} \rightarrow \infty, \cdots, n_{k} \rightarrow \infty$, if $f$ is continuous. Further, if $f$ has nondecreasing increments these polynomials have nonnegative second partial derivatives, as may be shown by repeated application of the formula

$$
(d / d x) \sum_{i=0}^{n}\left(\begin{array}{c}
n \\
i
\end{array}\right) a_{i} x^{i}(1-x)^{n-i}=n \sum_{i=0}^{n-1}\left(\begin{array}{c}
n-1 \\
i
\end{array}\right)\left(a_{i+1}-a_{i}\right) x^{i}(1-x)^{n-1-i} .
$$

3. A line integral inequality of Jensen's type. Perhaps the most direct analogue of Jensen's inequality for $f$ defined on an interval $I \subset R^{k}$ would involve the integral of $f$ over $I$ with respect to a normed measure. The inequality we treat here, however, deals with a line integral over a positively oriented curve. By the term "positively oriented curve" we understand a nondecreasing map $X=\left(X_{1}, \cdots, X_{k}\right)$ of a real interval $[\alpha, \beta)$ into an interval $I \subset R^{k}: \alpha \leqq t^{\prime} \leqq t^{\prime \prime}<\beta$ implies $X\left(t^{\prime}\right) \leqq X\left(t^{\prime \prime}\right)$, i.e., $X_{i}\left(t^{\prime}\right) \leqq X_{i}\left(t^{\prime \prime}\right)$ for $i=1,2, \cdots, k$. Theorem 3.1, below, relates such a map $X$ and a real valued function $G$ of bounded variation on $[\alpha, \beta)$. The integrals $\int_{[\alpha, \beta)} X d G$ and $\int_{[\alpha, \beta)} G d X$ appearing in the statement of Theorem 3.1 are related through the formula for integration by parts: $\int_{J} X d G+\int_{J} G d X=\int_{J} d(X G)$ for every interval $I \subset[\alpha, \beta)\left(\right.$ by $\int_{J} X d G$ we understand the vector $\left(\int_{J} X_{1} d G, \cdots, \int_{J} X_{k} d G\right)$, and similarly for $\left.\int_{J} G d x, \int_{J} d(X G)\right)$. In order for this to hold and also to avoid minor difficulties in the determination of $G$ at common points of discontinuity of $X$ and $G$, we shall assume henceforth without further reference that $X$ is nondecreasing and continuous from the right (i.e., $X_{i}$ is nondecreasing and continuous from the right for $i=1, \cdots, k$ ) and $G$ is continuous from the left. For simplicity of notation, we write $X(\beta)$ for $X\left(\beta^{-}\right)$and $G(\beta)$ for $G\left(\beta^{-}\right)$. Some further bits of notation will be required: the symbol $[\alpha, t\}$ will refer to either of the left intervals $[\alpha, t\}$ or $[\alpha, t)$; and $\{t, \beta)$ to either of the right intervals $[t, \beta)$ or $(t, \beta)$. Also, if $a=\left(a_{1}, \cdots, a_{k}\right) \in R^{k}$, then $a^{+}=\left(a_{1}^{+}, \cdots, a_{k}^{+}\right)$, where $a_{i}^{+}=\max \left(a_{i}, 0\right), i=1,2, \cdots, k$. Further, we set $\xi_{i}=\int_{[\alpha, \beta)} X_{i} d G, i=$ $1,2, \cdots, k$, and $\xi=\int_{[\alpha, \beta)} X d G$.

THEOREM 3.1. If $G(\alpha)=0$, then necessary and sufficient conditions in order that 


$$
\int_{[\alpha, \beta)} f[X(t)] d G(t) \geqq f\left[\int_{[\alpha, \beta)} X(t) d G(t)\right]
$$

for every continuous function $f$ on $I$ with nondecreasing increments are

$$
G(\beta)=1
$$

and

$$
\left\{\begin{array}{l}
\int_{[\alpha, t]} G d X \geqq 0 \text { for every left interval }[\alpha, t\} \subset[\alpha, \beta) \text { and } \\
\int_{(t, \beta)}[1-G] d X \geqq 0 \text { for every right interval }\{t, \beta) \subset[\alpha, \beta) .
\end{array}\right.
$$

The case $k=1$ of Theorem 3.1 appears in [1]. We note that for $k=1$ the class of continuous functions with nondecreasing increments is identical with that of continuous convex functions. If $k>1$, (3.2) (3.3) do not imply (3.1) for all continuous convex $f$. For example, set $X(t)=(0,2 t)$ for $0 \leqq t \leqq 1 / 2, X(t)=(2 t-1,1)$ for $1 / 2 \leqq t \leqq 2, G(0)=$ $0, G(2)=1$, and let $G$ have saltus 1 at $t=0$, saltus -1 at $t=1 / 2$, and saltus 1 at $t=1$, being constant on each of the intervening intervals. Set $f(x)=\left(x_{1}-x_{2}\right)^{2}$, where $x=\left(x_{1}, x_{2}\right)$; then $f$ is convex, but does not have nondecreasing increments. We have $\int_{[0,2)} f[X(t)] d G(t)=-1$, while $f\left[\int_{[0,2)} X(x) d G(t)\right]=1$, so that (3.1) fails, although (3.2) and (3.3) are satisfied: indeed, $0 \leqq G \leqq 1$ (cf. Lemma 3.1).

Before proceeding to the proof of Theorem 3.1, we examine relations among the following properties of $G$, for given $X$ :

$$
0 \leqq G(t) \leqq 1 \text { for } t \in[\alpha, \beta) ;
$$

$$
\left\{\begin{array}{l}
\int_{[\alpha, t\}} G d X \geqq 0 \text { for every left interval }[\alpha, t\} \subset[\alpha, \beta), \text { and } \\
\int_{\{t, \beta)}[1-G] d X \geqq 0 \text { for every right interval }\{t, \beta] \subset[\alpha, \beta) ;
\end{array}\right.
$$

$$
\begin{aligned}
& \begin{cases}\int_{[\alpha, t]} G d X \geqq\left[X\left(t^{+}\right)-\xi\right]^{+} & \text {for } t \in[\alpha, \beta) ， \\
\int_{[\alpha, t)}^{\infty} G d X \geqq\left[X\left(t^{-}\right)-\xi\right]^{+} & \text {for } t \in[\alpha, \beta) ;\end{cases} \\
& \begin{cases}\int_{[t, \beta)}[1-G] d X \geqq\left[\xi-X\left(t^{-}\right)\right]^{+} & \text {for } t \in[\alpha, \beta), \\
\int_{(t, \beta)}[1-G] d X \geqq\left[\xi-X\left(t^{+}\right)\right]^{+} & \text {for } t \in[\alpha, \beta) .\end{cases}
\end{aligned}
$$

LEMma 3.1. We have (3.4) $\Rightarrow$ (3.3). Also, if $G(\alpha)=0$ and $G(\beta)=$ 1 , then $(3.3) \Leftrightarrow(3.5) \Leftrightarrow(3.6)$. 
Proof. That (3.4) implies (3.3) is obvious. Also, if $G(\alpha)=0$, $G(\beta)=1$, then

$$
\xi=\int_{[\alpha, \beta)} X d g=X(\alpha)+\int_{[\alpha, \beta)}(1-G) d X,
$$

so that

$$
\int_{[t, \beta)}(1-G) d X=\xi-X(\alpha)-\int_{[\alpha, t]}(1-G) d X,
$$

where $[\alpha, t\} \cup\{t, \beta)$ is a disjoint partition of $[\alpha, \beta)$; or,

$$
\left\{\begin{array}{l}
\int_{[t, \beta)}(1-G) d X=\xi-X\left(t^{-}\right)+\int_{[\alpha, t)} G d X, \\
\int_{(t, \beta)}(1-G) d X=\xi-X\left(t^{+}\right)+\int_{[\alpha, t]}^{G} G d X .
\end{array}\right.
$$

Thus (3.3) implies that

$$
\int_{[\alpha, t)} G d X \geqq X\left(t^{-}\right)-\xi, \quad \int_{[\alpha, t]} G d X \geqq X\left(t^{+}\right)-\xi .
$$

With the first inequality in (3.3), this implies (3.5). Thus (3.3) $\Rightarrow(3.5)$. Also, it is clear from (3.7) that (3.5) and (3.6) are equivalent. Finally, (3.5) and (3.6) clearly imply (3.3), and the proof of Lemma 3.1 is complete.

Lemma 3.2 will be used in the proof of the sufficiency of the conditions in Theorem 3.1.

LEMma 3.2. Under the hypotheses of Theorem 3.1, and conditions (3.2) and (3.3),

$$
\int_{[\alpha, \beta)} \nabla f[X(t)] \cdot d[X(t)-\xi]^{+} \leqq f[X(\beta)]-f(\xi) .
$$

Proof. We observe first that $X(\alpha) \leqq \xi \leqq X(\beta)$. This follows from the inequalities

$$
0 \leqq \int_{[\alpha, \beta)} G(u) d X(u)=X(\beta)-\int_{[\alpha, \beta)} X(u) d G(u)=X(\beta)-\xi,
$$

and

$$
0 \leqq \int_{[\alpha, \beta)}[1-G(u)] d X(u)=-X(\alpha)+\int_{[\alpha, \beta)} X(u) d G(u)=\xi-X(\alpha) .
$$

Since $X$ is nondecreasing, there is, for $i=1,2, \cdots, k$, a unique smallest real number $\tau_{i}$ such that $X_{i}\left(\tau_{i}^{-}\right) \leqq \xi_{i} \leqq X_{i}\left(\tau_{i}^{+}\right)$. Suppose $\tau_{1} \leqq \tau_{2} \leqq$ $\cdots \leqq \tau_{k}$; the proof is similar for other orderings. We have 


$$
\begin{aligned}
& \int_{[\alpha, \beta)} \nabla f[X(t)] \cdot d[X(t)-\xi]^{+} \\
& =\sum_{i=1}^{k} \int_{[\alpha, \beta)} f_{i}[X(t)] d\left[X_{i}(t)-\xi_{i}\right]^{+} \\
& =\sum_{i=1}^{k} \int_{\left[\tau_{i}, \beta\right)} f_{i}[X(t)] d X_{i}(t) \\
& =\int_{\left[\tau_{k}, \beta\right)} \sum_{i=1}^{k} f_{i}[X(t)] d X_{i}(t)+\int_{\left[\tau_{k-1}, \tau_{k}\right)} \sum_{i=1}^{k-1} f_{i}[X(t)] d X_{i}(t) \\
& \quad+\cdots+\int_{\left[\tau_{1}, \tau_{2}\right)} f_{1}[X(t)] d X_{1}(t) .
\end{aligned}
$$

Since $f_{i}(x)=f_{i}\left(x_{1}, \cdots, x_{k}\right)$ is nondecreasing in each argument, $i=$ $1,2, \cdots, k$, we have, for $1 \leqq i<j \leqq k$, and for $\tau_{j-i} \leqq t<\tau_{j}$,

$$
\begin{aligned}
& f_{i}\left[X_{1}(t), \cdots, X_{k}(t)\right] \\
& \quad \leqq f_{i}\left[X_{1}(t), \cdots, X_{j-i}(t), X_{j}\left(\tau_{j}^{-}\right), X_{j+1}\left(\tau_{j+1}^{-}\right), \cdots, X_{k}\left(\tau_{k}^{-}\right)\right] \\
& \quad \leqq f_{i}\left[X_{1}(t), \cdots, X_{j-1}(t), \xi_{j}, \cdots, \xi_{k}\right]
\end{aligned}
$$

It follows that

$$
\begin{aligned}
& \int_{\left[\tau_{j-1}, \tau_{j}\right)} \sum_{i=1}^{j-1} f_{i}[X(t)] d X_{i}(t) \\
& \quad \leqq \int_{\left[\tau_{j-1}, \tau_{j}\right)} \sum_{i=1}^{j-1} f_{i}\left[X_{1}(t), \cdots, X_{j-1}(t), \xi_{j}, \cdots, \xi_{k}\right] d X_{i}(t) \\
& =\int_{\left[\tau_{j-1}, \tau_{j}\right)} \nabla f\left[X_{1}(t), \cdots, X_{j-1}(t), \xi_{j}, \cdots, \xi_{k}\right] \\
& \quad \cdot d\left[X_{1}(t), \cdots, X_{j-1}(t), \xi_{j}, \cdots, \xi_{k}\right] \\
& =f\left[X_{1}\left(\tau_{j}^{-}\right), \cdots, X_{j-1}\left(\tau_{j}^{-}\right), \xi_{j}, \cdots, \xi_{k}\right] \\
& \quad-f\left[X_{i}\left(\tau_{j-1}^{-}\right), \cdots, X_{j-1}\left(\tau_{j-1}^{-}\right), \quad \xi_{j}, \cdots, \xi_{k}\right], j=2, \cdots, k
\end{aligned}
$$

Therefore

$$
\begin{aligned}
\int_{[\alpha, \beta)} & \nabla f[X(t)] \cdot d[X(t)-\xi]^{+} \leqq f\left[X_{1}(\beta), \cdots, X_{k}(\beta)\right] \\
& -f\left[X_{1}\left(\tau_{k}^{-}\right), \cdots, X_{k-1}\left(\tau_{k}^{-}\right), \xi_{k}\right] \\
& +\sum_{j=2}^{k}\left\{f\left[X_{1}\left(\tau_{j}^{-}\right), \cdots, X_{j-1}\left(\tau_{j}^{-}\right), \xi_{j}, \cdots, \xi_{k}\right]\right. \\
& \left.-f\left[X_{1}\left(\tau_{j-1}^{-}\right), \cdots, X_{j-2}\left(\tau_{j-1}^{-}\right), \xi_{j-1}, \cdots, \xi_{k}\right]\right\} \\
& =f[X(\beta)]-f(\xi) .
\end{aligned}
$$

'This completes the proof of Lemma 3.2.

Proof of Theorem 3.1; necessity. Equation (3.2) follows from (3.1) with $f \equiv 1$ and $f \equiv-1$. For $1 \leqq i \leqq k$, and $\alpha \leqq t<\beta$, set $f(x)=$ $f\left(x_{1}, \cdots, x_{k}\right) \equiv\left[x_{i}-X_{i}\left(t^{-}\right)\right]^{+}$. For this function $f$, (3.1) yields 


$$
\int_{[\alpha, \beta)}\left[X_{i}(u)-X_{i}\left(t^{-}\right)\right]^{+} d G(u) \geqq\left[\xi_{i}-X_{i}\left(t^{-}\right)\right]^{+}
$$

But

$$
\begin{aligned}
\int_{[\alpha, \beta)}\left[X_{i}(u)-X_{i}\left(t^{-}\right)\right]^{+} d G(u) & =\int_{[t, \beta)}\left[X_{i}(u)-X_{i}\left(t^{-}\right)\right] d G(u) \\
& =\int_{[t, \beta)}[1-G(u)] d X_{i}(u)
\end{aligned}
$$

iso that

$$
\int_{[t, \beta)}[1-G(u)] d X_{i}(u) \geqq\left[\xi_{i}-X_{i}\left(t^{-}\right)\right]^{+}, \quad i=1,2, \cdots, k,
$$

verifying the first part of (3.6). The verification of the second part is similar. With Lemma 3.1, this completes the proof of the necessity of (3.2) and (3.3).

Sufficiency. Set $Q(t)=\left(Q_{1}(t), \cdots, Q_{k}(t)\right)=\int_{[\alpha, t)} G(u) d X(u)$ for $\alpha \leqq$ $t<\beta$. Then by (3.5) we have $Q\left(t^{ \pm}\right) \geqq\left[X\left(t^{ \pm}\right)-\xi\right]^{+}$for $\alpha \leqq t<\beta$. Since $f$ can be approximated uniformly in $I$ by polynomials with nondecreasing increments, there is no loss in generality in assuming that the partial derivatives $f_{i}(x), i=1,2, \cdots, k$, exist and are nondecreasing in each argument. We then have, for $i=1,2, \cdots, k$,

$$
\begin{aligned}
\int_{[\alpha, \beta)} f_{i}[X(t)] d Q_{i}(t) & =f_{i}[X(\beta)] Q_{i}(\beta)-\int_{[\alpha, \beta)} Q_{i}(t) d f_{i}[X(t)] \\
& \leqq f_{i}[X(\beta)] Q_{i}(\beta)-\int_{[\alpha, \beta)}\left[X_{i}(t)-\xi\right]^{+} d f_{i}[X(t)] \\
& =\int_{[\alpha, \beta)} f_{i}[X(t)] \mathrm{d}\left[X_{i}(t)-\xi\right]^{+},
\end{aligned}
$$

since

$$
Q(\beta)=[X(\beta)-\xi]=[X(\beta)-\xi]^{+}
$$

by (3.7). Therefore

$$
\begin{aligned}
\int_{[\alpha, \beta)} f[X(t)] d G(t) & =f[X(\beta)]-\int_{[\alpha, \beta])} G(t) \nabla f[X(t)] \cdot d X(t) \\
& =F[X(\beta)]-\int_{[\alpha, \beta)} \nabla f[X(t)] \cdot d Q(t) \\
& \geqq f[X(\beta)]-\int_{[\alpha, \beta)} \nabla f[X(t)] \cdot d[X(t)-\xi]^{+} \geqq f(\xi)
\end{aligned}
$$

by Lemma 3.2. This completes the proof of the theorem.

In each of the following corollaries, Corollary 3.1 and Corollary 3.2 , it is assumed that $X$ is a nondecreasing map, continuous from the 
right, from $[\alpha, \beta)$ into a $k$-dimensional interval $I$ containing the origin $0=(0, \cdots, 0)$; that $f$ is a continuous function from $I$ into the reals which has nondecreasing increments; that $G$ is a real-valued function of bounded variation on $[\alpha, \beta)$, continuous from the left, and that $G(\beta)=1$.

CoRollary 3.1. If $X(\alpha)=0=(0, \cdots, 0)$, if $f(0) \leqq 0$, if $G(\alpha) \geqq$ 0 , and if (3.3) holds, then

$$
\int_{[\alpha, \beta)} f[X(t)] d G(t) \geqq f\left[\int_{[\alpha, \beta)} X(t) d G(t)\right] .
$$

The case $k=1$ of this corollary appears in [1].

Proof. Set $G_{1}(t)=G(t)$ for $t>\alpha, G_{1}(\alpha)=0$. Then by Theorem 3.1,

$$
\int_{[\alpha, \beta)} f[X(t)] d G_{1}(t) \geqq f\left[\int_{[\alpha, \beta)} X(t) d G_{1}(t)\right] .
$$

But

$$
\int_{[\alpha, \beta)} X(t) d G_{1}(t)=\int_{[\alpha, \beta)} X(t) d G(t)
$$

since $X(\alpha)=0$. Also

$$
\int_{[\alpha, \beta)} f[X(t)] d G_{1}(t)=f(0) G(\alpha)+\int_{[\alpha, \beta)} f[X(t)] d G(t),
$$

and (3.1) follows.

\section{COROLlaRY 3.2. If either}

(i) $G(\alpha)=0$ or

(ii) $X(\alpha) \geqq 0, f(0) \leqq 0$, and if

(iii) $0 \leqq G(t) \leqq 1$ for $\alpha \leqq t<\beta$,

then

$$
\int_{[\alpha, \beta)} f[X(t)] d G(t) \geqq f\left[\int_{[\alpha, \beta)} X(t) d G(t)\right] .
$$

Proof. By Lemma 3.1, (iii) implies (3.3) so that under hypotheses (i) and (iii), (3.1) is immediate from Theorem 3.1. If (ii) and (iii) hold, choose $\alpha^{*}<\alpha$, set $X^{*}\left(\alpha^{*}\right)=0, X^{*}(t)=X(t)$ for $\alpha \leqq t<\beta$, and let. $X^{*}$ be linear for $\alpha^{*} \leqq t \leqq \alpha$. Set $G^{*}\left(\alpha^{*}\right)=0, G^{*}(t)=G(\alpha)$ for $\alpha^{*} \leqq$ $t \leqq \alpha, G^{*}(t)=G(t)$ for $\alpha \leqq t<\beta$. Then $G^{*}(\beta)=1, G^{*}\left(\alpha^{*}\right)=0$, and $0 \leqq G^{*} \leqq 1$. From Lemma 3.1 and Theorem 3.1 it follows that

$$
\int_{\left[\alpha^{*}, \beta\right)} f\left[X^{*}(t)\right] d G(t) \geqq f\left[\int_{\left[\alpha^{*}, \beta\right)} X^{*}(t) d G^{*}(t)\right] .
$$

But 


$$
\int_{\left[\alpha^{*}, \beta\right)} X^{*}(t) d G^{*}(t)=\int_{[\alpha, \beta)} X(t) d G(t)
$$

and

$$
\int_{\left[\alpha^{*}, \beta\right)} f\left[X^{*}(t)\right] d G^{*}(t)=f(0) G(\alpha)+\int_{[\alpha, \beta)} f[X(t)] d G(t),
$$

Since $f(0) \leqq 0$ and $G(a) \geqq 0$, conclusion (3.1) follows.

Remarks on Corollary 3.2. The case $k=1$ of Corollary 3.2 appears in [1] with the hypothesis $X(\alpha)=0$. With a change of variable in Corollary 3.2 we obtain the following theorem.

Let $Y$ be a nonincreasing map, continuous from the left, from $\{0,1]$ into $I \subset R^{k}$, with $Y(1) \geqq 0$. Let $H$ be continuous from the right and of bounded variation on $(0,1]$, and suppose $H(0)=0, H(t) \geqq 0$ on $(0,1], \int_{(0,1]}|d H(t)|>0$. If $f$ is continuous with nondecreasing increments on $I$, and if $f(0) \leqq 0$, then

$$
\int_{(0,1]} f(Y) d H / \int_{(0,1]}|d H| \geqq f\left(\int_{(0,1]} Y d H / \int_{(0,1]}|d H|\right) .
$$

It suffices to set $X(t)=Y(1-t), G(t)=1-\left[H(1-t) / \int_{(0,1]} d H(t)\right]$ on $[0,1)$ in Corollary 3.2. Cases $k=1$ and $k=2$ of this latter theorem, for discrete and for continuous $H$, appear in [2], with additional hypotheses: for $k=1$, that $f^{\prime}$ is convex; and for $k=2$, that the first partial derivatives are convex along positively oriented lines.

Ciesielski points out (in the two-dimensional case) that setting $f\left(x_{1}, x_{2}\right)=x_{1} x_{2}$ yields a generalization of an inequality of Chebyshev [3, page 43]: if $Y_{1}, Y_{2}$ are nonincreasing, nonnegative and continuous from the left on $(0,1]$, if $H$ is continuous from the right and of bounded variation on $(0,1]$, and if $H(0)=0, H(t) \geqq 0$ on $(0,1]$, then

$$
\int_{(0,1]} Y_{1} Y_{2} d H \int_{(0,1]}|d H| \geqq \int_{(0,11} Y_{1} d H \int_{(0,1]} Y_{2} d H \text {. }
$$

COROLLARY 3.3. Let $f$ be a continuous map from a k-dimensional interval $I$ containing the origin into the reals, with nondecreasing increments, such that $f(0) \leqq 0$. Let $m$ be a positive integer, and let $\quad 1 \geqq h_{1} \geqq h_{2} \geqq \cdots \geqq h_{m} \geqq 0$. Let $a_{j} \in I, j=1,2, \cdots, m$, with $(1, \cdots, 1)>a_{1} \geqq a_{2} \geqq \cdots \geqq a_{m} \geqq(0, \cdots, 0)$. Then

$$
\sum_{j=1}^{m}(-1)^{j-1} h_{j} f\left(a_{j}\right) \geqq f\left[\sum_{j=1}^{m}(-1)^{j-1} h_{j} a_{j}\right] .
$$

For inequality (3.1) becomes (3.8) if $\alpha=0, \beta=1$, if $G$ has saltus $(-1)^{j-1} h_{j}$ at $1-j / m,(j=1,2, \cdots, m)$ with $G(1)=1$, and if $X(1-j / m)=$ 
$a_{j}(j=1,2, \cdots, m)$.

The one-dimensional case appears in [1], and was proved independently by Olkin [5]. For references to earlier special cases by Szegö, Weinberger, and Bellman, cf. [5].

\section{An inequality of Levin and Stečkin.}

THEOREM 4.1. Let $I$ denote an interval in $R^{k}$; let $X$ be a nondecreasing map from $[\alpha, \beta)$ into $I$, continuous from the right. Let $H$ be continuous from the left and of bounded variation on $[\alpha, \beta)$, with $H(\alpha)=0$. Then,

$$
\int_{[\alpha, \beta)} f[X(t)] d H(t) \geqq 0
$$

for every continuous function $f$ from $I$ into $R$ with nondecreasing increments, if and only if

$$
\begin{gathered}
H(\beta)=0, \\
\int_{[\alpha, \beta)} H(u) d X(u)=0,
\end{gathered}
$$

and

$$
\int_{[\alpha, t]} H(u) d X(u) \geqq 0 \quad \text { for } \quad[\alpha, t\} \subset[\alpha, \beta)
$$

Proof of necessity. The validity of (4.1) for $f \equiv 1$ and for $f \equiv-1$ implies (4.2). Further, (4.1) for $f(x) \equiv x_{j}$, where $x=\left(x_{1}, \cdots, x_{k}\right)$, and for $f(x) \equiv-x_{j}(j=1,2, \cdots, k)$, implies $\int_{[\alpha, \beta)} X_{j}(u) d H(u)=0, j=$ $1,2, \cdots, k$, or, equivalently, $\int_{[\alpha, \beta)} H(u) d X(u) \stackrel{[\alpha, \beta)}{=} 0$, which is (4.3). Inequality (4.4) results from (4.1) after integration by parts, on setting, for fixed $j(j=1,2, \cdots, k)$ and fixed $t, \alpha \leqq t<\beta, f(x)=\left[X_{j}\left(t^{+}\right)-x_{j}\right]^{+}$ or $\left[X_{j}\left(t^{-}\right)-x_{j}\right]^{+}$.

Proof of sufficiency. Since, as remarked in $\S 2, f$ may be approximated uniformly on $I$ by functions with continuous nonnegative second partial derivatives, we may assume that the second partials $f_{i j}$ exist. and are continuous and nonnegative. We then have

$$
\begin{aligned}
\int_{[\alpha, \beta)} f[X(t)] d H(t) & =-\int_{[\alpha, \beta)} H(t) \nabla f[X(t)] \cdot d X(t) \\
& =-\sum_{j=1}^{k} \int_{[\alpha, \beta)} f_{j}[X(t)] H(t) d X_{j}(t) \\
& =\sum_{j=1}^{k} \sum_{i=1}^{k} \int_{[\alpha, \beta)} f_{i j}[X(t)] d X_{i}(t) \int_{[0, t)} H(u) d X_{j}(u),
\end{aligned}
$$


by (4.2) and (4.3). But by (4.4) each term in the last sum is nonnegative, so that (4.1) is verified.

The one-dimensional $(k=1)$ version of Theorem 4.1 appears as. Theorem D.1 in [4], and indeed the proof of Theorem 4.1 is the natural extension of the proof given in [4].

Sufficiency in the one-dimensional $(k=1)$ version of Theorem 3.1 was proved in [1] as a consequence of Theorem 249 in [3]; it is exhibited below for continuous $X$ as a consequence also of Levin and Stečkin's. Theorem D.1 (Theorem 4.1 above, with $k=1$ ). Choose $\tau$ so that $X(\tau)=\xi=\int_{[\alpha, \beta)} X(t) d G(t)$. Set $H(t)=G(t)$ for $\alpha \leqq t<\tau, H(t)=G(t)-1$ for $\tau \leqq t<\beta$. Then $H(\alpha)=0, H(\beta)=0$. Also

$$
\begin{aligned}
\int_{[\alpha, \beta)} H(u) d X(u) & =\int_{[\alpha, \beta)} G(u) d X(u)-\int_{[\tau, \beta)} d X(u) \\
& =X(\beta)-\xi-[X(\beta)-X(\tau)]=0 ;
\end{aligned}
$$

and

$$
\int_{[\alpha, t]} H(u) d X(u)=\int_{[\alpha, t\}} G(u) d X(u) \geqq 0
$$

if $\alpha \leqq t<\tau$, while

$$
\begin{aligned}
\int_{[\alpha, t\}} H(u) d X(u) & =\int_{[\alpha, t\}} G(u) d X(u)-\int_{[\tau, t]} d X(u) \\
& =\int_{[\alpha, t\}} G(u) d X(u)-\left[X\left(t^{ \pm}\right)-\xi\right] \geqq_{\mathbf{a}}^{*} 0
\end{aligned}
$$

for $\tau \leqq t<\beta$. From (4.1) it then follows that

$$
\int_{[\alpha, \beta,} f[X(t)] d H(t)=\int_{[\alpha, \beta)} f[X(t)] d G(t)-f(\xi) \geqq 0,
$$

which is $(3.1)$.

\section{REFERENCES}

1. H. D. Brunk, On an inequality for convex functions, Proc. Amer. Math. Soc., 7 (1956), 817-824.

2. Z. Ciesielski, A Note on Some Inequalities of Jensen's Type, Annales Polonici Mathematici, 4 (1957-58), 269-274.

3. G. H. Hardy, J. E. Littlewood, G. Polya, Inequalities, Cambridge University Press, Second Edition, 1952.

4. V. T. Levin, and S. B. Stečkin, Inequalities, Amer. Math. Soc. Translations, vol. 14, pp. 1-29 (from appendices to Russian edition of [3]).

5. I. Olkin, On Inequalities of Szegö and Bellman, Proc. Nat'l. Acad. of Soc., 45 (1959), 230-231. 



\section{PACIFIC JOURNAL OF MATHEMATICS}

\section{EDITORS}

\author{
Robert Osserman \\ Stanford University \\ Stanford, California
M. G. Arsove
University of Washington
Seattle 5 , Washington

\author{
J. DugundJI \\ University of Southern California \\ Los Angeles 7, California
}

Lowell J. Paige

University of California

Los Angeles 24, California

\section{ASSOCIATE EDITORS}
E. F. BECKENBACH
B. H. NeumanN
F. WOLF
K. YOSIDA

\section{SUPPORTING INSTITUTIONS}

\author{
UNIVERSITY OF BRITISH COLUMBIA \\ CALIFORNIA INSTITUTE OF TECHNOLOGY \\ UNIVERSITY OF CALIFORNIA \\ MONTANA STATE UNIVERSITY \\ UNIVERSITY OF NEVADA \\ NEW MEXICO STATE UNIVERSITY \\ OREGON STATE UNIVERSITY \\ UNIVERSITY OF OREGON \\ OSAKA UNIVERSITY \\ UNIVERSITY OF SOUTHERN CALIFORNIA
}

\author{
STANFORD UNIVERSITY \\ UNIVERSITY OF TOKYO \\ UNIVERSITY OF UTAH \\ WASHINGTON STATE UNIVERSITY \\ UNIVERSITY OF WASHINGTON \\ * * * * \\ AMERICAN MATHEMATICAL SOCIETY \\ CALIFORNIA RESEARCH CORPORATION \\ SPACE TECHNOLOGY LABORATORIES \\ NAVAL ORDNANCE TEST STATION
}

Mathematical papers intended for publication in the Pacific Journal of Mathematics should by typewritten (double spaced), and on submission, must be accompanied by a separate author's résumé. Manuscripts may be sent to any one of the four editors. All other communications to the editors should be addressed to the managing editor, L. J. Paige at the University of California, Los Angeles 24, California.

50 reprints per author of each article are furnished free of charge; additional copies may be obtained at cost in multiples of 50 .

The Pacific Journal of Mathematics is published quarterly, in March, June, September, and December. Effective with Volume 13 the price per volume (4 numbers) is $\$ 18.00$; single issues, $\$ 5.00$. Special price for current issues to individual faculty members of supporting institutions and to individual members of the American Mathematical Society: $\$ 8.00$ per volume; single issues $\$ 2.50$. Back numbers are available.

Subscriptions, orders for back numbers, and changes of address should be sent to Pacific Journal of Mathematics, 103 Highland Boulevard, Berkeley 8, California.

Printed at Kokusai Bunken Insatsusha (International Academic Printing Co., Ltd.), No. 6, 2-chome, Fujimi-cho, Chiyoda-ku, Tokyo, Japan.

PUBLISHED BY PACIFIC JOURNAL OF MATHEMATICS, A NON-PROFIT CORPORATION

The Supporting Institutions listed above contribute to the cost of publication of this Journal, but they are not owners or publishers and have no responsibility for its content or policies. 


\section{Pacific Journal of Mathematics}

\section{Vol. 14, No. $3 \quad$ July, 1964}

Erik Balslev and Theodore William Gamelin, The essential spectrum of a class of ordinary differential operators . . . . . . . . . . . . . . . . . . . .

James Henry Bramble and Lawrence Edward Payne, Bounds for derivatives in

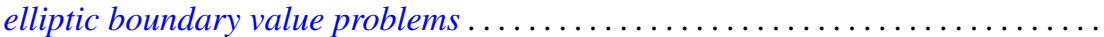

Hugh D. Brunk, Integral inequalities for functions with nondecreasing

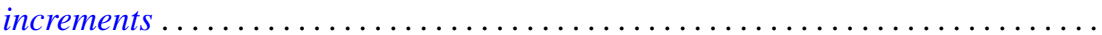

William Edward Christilles, A result concerning integral binary quadratic

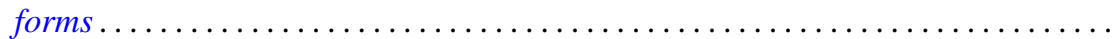

Peter Crawley and Bjarni Jónsson, Refinements for infinite direct decompositions of

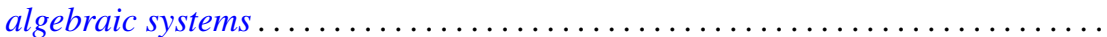

Don Deckard and Carl Mark Pearcy, On continuous matrix-valued functions on a Stonian space.

Raymond Frank Dickman, Leonard Rubin and P. M. Swingle, Another

characterization of the $n$-sphere and related results $\ldots \ldots \ldots \ldots \ldots \ldots$

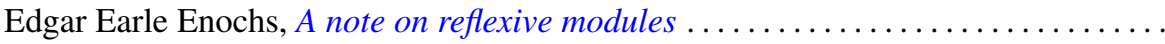

Vladimir Filippenko, On the reflection of harmonic functions and of solutions of the

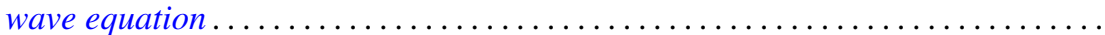

Derek Joseph Haggard Fuller, Mappings of bounded characteristic into arbitrary

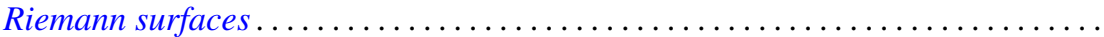
895

Curtis M. Fulton, Clifford vectors . . . . . . . . . . . . . . . . . . . . . . . . . . . . . . 917

Irving Leonard Glicksberg, Maximal algebras and a theorem of Radó . .

919

Kyong Taik Hahn, Minimum problems of Plateau type in the Bergman metric

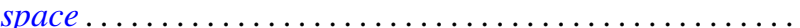

A. Hayes, A representation theory for a class of partially ordered rings...

J. M. C. Joshi, On a generalized Stieltjes trasform

J. M. C. Joshi, Inversion and representation theorems for a generalized Laplace transform ...

Eugene Kay McLachlan, Extremal elements of the convex cone $B_{n}$ of functions ...

Robert Alan Melter, Contributions to Boolean geometry of p-rings ...

James Ronald Retherford, Basic sequences and the Paley-Wiener criterion . . . . . . . 1019

Dallas W. Sasser, Quasi-positive operators. .

Oved Shisha, On the structure of infrapolynomials with prescribed coefficients ..

Oved Shisha and Gerald Thomas Cargo, On comparable means

Maurice Sion, A characterization of weak ${ }^{*}$ convergence ........

Morton Lincoln Slater and Robert James Thompson, A permanent inequality for

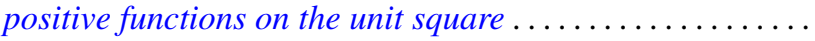

David A. Smith, On fixed points of automorphisms of classical Lie algebras ...

Sherman K. Stein, Homogeneous quasigroups ................

J. L. Walsh and Oved Shisha, On the location of the zeros of some infrapolynomials with prescribed coefficients .

Ronson Joseph Warne, Homomorphisms of $d$-simple inverse semigroups with identity . 